\title{
Cuándo, por qué y para qué la eduación intercultural. Discursos y praxis de la educación intercultural
}

\section{María García-Cano Torrico}

Universidad de Granada. Departamento de Antropología Social mgcano@ugr.es

\section{Esther Márquez Lepe}

The Center for Cross-Cultural Study

emarquez@ugr.es

\section{Belén Agrela Romero}

Universidad de Jaén. Escuela Universitaria de Trabajo Social

bagrela@ujaen.es

\section{Resumen}

El artículo analiza, desde una perspectiva antropológica, la experiencia en la coordinación de un proyecto europeo sobre educación intercultural, titulado CLIEC (Cooperative Learning in European Contexts). Las reflexiones que aquí presentamos sobre las distintas actuaciones realizadas en el marco de dicho proyecto tienen por objeto sistematizar, por una parte, las distintas intenciones y actividades propuestas, y, por otra, contribuir al debate teórico actual sobre cómo se está construyendo y gestionando la noción de interculturalidad dentro del ámbito educativo. Para ello, hemos dedicado un especial interés al cuestionamiento y a la reformulación de los principios que hasta ahora vienen presidiendo la intervención sobre educación intercultural en el contexto español. De este modo, las autoras se sirven del análisis de los discursos y de las prácticas definidas como de interculturalidad para interrogarse sobre el cuándo, el porqué y el para qué de la educación intercultural en las aulas.

Palabras clave: educación, interculturalidad, inmigración, aprendizaje cooperativo, España.

\section{Abstract. When, how and why of intercultural education. Discourses and praxis of intercultural education}

This article analyse, from an anthropological perspective, the coordination experience of an European project on intercultural education titled CLIEC (Cooperative Learning in European Contexts). The thoughts we are putting forward here related on the different actions realized in this project have the object of, on the one hand, systematizing the diverse motives and activities proposed. And, on the other hand, contributing to the current theoretical debate on how the intercultural notion is being constructed and managed into the Education scope. For getting it, we have shown an special interest on the challenge and re-formulation of the fundamentals are holding the intercultural education intervention in the Spanish context. In this way, the authors are drawing on the discourses and practices defined in the name of interculturality in order to cross-examine on the when, why and what for of the Intercultural Education in the classroom.

Key words: education, interculturality, immigration, cooperative learning, Spain. 


\section{Sumario}

Notas introductorias

1. Primeros contactos con la comunidad educativa

2. Revisión de presupuestos teóricos: el discurso cultural
3. Actuaciones interculturales en el ámbito escolar

4. A modo de conclusión. Cuestionando cuándo, por qué y para qué la educación intercultural

Referencias bibliográficas

\section{Notas introductorias}

Este artículo pretende ser una reflexión concerniente a nuestra actuación como coordinadoras de un proyecto europeo sobre educación intercultural desarrollado en distintos colegios de la provincia de Huelva, en Andalucía ${ }^{1}$. Se enmarca dentro del programa europeo Comenius ${ }^{2}$ y recibe el nombre de CLIEC (Cooperative Learning in European Contexts), traducido en su versión castellana como AMIGHA (Aprendizaje Multicultural e Instructivo con Grupos Heterogéneos en el Aula). Su realización en los colegios está significando la implementación de una metodología basada en el aprendizaje cooperativo ${ }^{3}$ (metodología CLIM - Cooperative Learning in Multicultural Groups), cuyos objetivos se concretan en una serie de unidades didácticas CLIM ${ }^{4}$ dirigidas al alumnado de entre nueve y doce años.

A través de la reflexión sobre nuestra experiencia, el propósito principal que nos planteamos con este artículo es contribuir al análisis, a la conceptualización y al debate en torno a la construcción de significados que, sobre la educación intercultural, se viene realizando en el contexto educativo y escolar

1. Los colegios que participan en el proyecto se sitúan en las localidades de Moguer, Almonte y Bonares, pertenecientes a la comarca del Condado, en la zona oriental de la provincia de Huelva, al sur occidental de España.

2. Del Programa Socrates: Acción 2.1 Training of School Education Staff. Convocatoria del 1 de marzo del 2002, siendo concedido para ser desarrollado durante treinta y seis meses a partir del pasado 1 de octubre del 2002.

3. La aplicación de la metodología del «aprendizaje cooperativo» al trabajo con grupos multiculturales surgió en Bélgica, en la región de Flandes, en 1995, a raíz de que el Center for Intercultural Education adaptara el método de aprendizaje «instrucción compleja» (CI) para dar forma a la educación intercultural en los centros educativos. La base teórica del CI fue desarrollada anteriormente por la profesora Elizabeth Cohen y su equipo de la Escuela de Educación de la Universidad de Stanford en California (EEUU). El objetivo fundamental de Cohen era provocar el aprendizaje y desarrollar las destrezas intelectuales y sociales del alumnado partiendo de sus propias capacidades y conocimientos. De este modo, el aprendizaje cooperativo, a través de la interacción del alumnado, se convierte en el modo de trabajar la interculturalidad bajo dos premisas básicas: eliminar las diferencias de estatus y hacer uso de las múltiples habilidades asignando competencias a todo el alumnado.

4. El total de unidades elaboradas en el contexto flamenco han sido seis, editadas por el Steunpunt ICO (Center for Intercultural Education de Gante, Bélgica). La tres unidades que han sido traducidas y adaptadas al contexto español llevan por título: Unidad 1 ¿Hacemos una fiesta juntos?; Unidad 2 ¿Te falta un tornillo?, y Unidad 3 ¿Cara o cruz? 
actual en España. Para dicho análisis, nos servimos de los aportes y las posibilidades que dotaron el poder ubicarnos en un espacio privilegiado, como fue el de la coordinación del proyecto, lo que nos permitió una mirada diferente sobre el proceso acerca de cómo se construye, da sentido y se aplica la noción de interculturalidad. Aspecto que consideramos novedoso en la medida en la que nos colocó en una posición a caballo entre la dimensión cognitiva de creación de conocimiento y la dimensión práctica de aplicación del mismo.

La manera de participar en este proyecto nos sirve como hilo conductor de esta exposición, pero además se nos revela como herramienta clave de disertación para dos propósitos que discurren en paralelo en este artículo. Por un lado, ejercer de antropólogas (y no meramente de "gestoras de proyectos») que, insertas en el campo, aspiran a mejorar el conocimiento de la realidad en la que intervenimos, conscientes de que esto supondrá en muchas ocasiones la elaboración de nuevos interrogantes, de plantear contradicciones propias $y$, sobre todo, de interpretar críticamente el impacto que ejerce el desarrollo del proyecto que nosotras mismas dirijimos. De cómo los investigadores y las investigadoras ejercemos igualmente como personas constructoras de conocimiento y de la propia realidad sobre la que investigamos. Y, en segundo lugar, nuestra intención es también la de argumentar en torno a cuestiones que abren el debate actual sobre educación intercultural y multiculturalismo, entendido éste como movimiento social y como discurso interesado en la construcción constante de identidades — múltiples y heterogéneas - basadas en las diferencias culturales, raciales y étnicas de colectivos tradicionalmente estigmatizados y discriminados (Dietz, 2003).

El modo de proceder que proponemos para desenmarañar todos estos aspectos es un recorrido de ida y vuelta de manera sucesiva, es decir, de la práctica a la teoría y de ahí, de nuevo, a la práctica. De este modo, describiremos las distintas pautas y decisiones que fuimos adoptando a lo largo de las distintas fases del proyecto, explicitando en paralelo los principios teóricos que configuraron nuestro posicionamiento, así como el análisis y la interpretación del propio contexto con el que nos encontramos.

Este proceso de reflexión e interpretación constante que buscábamos mantener no nos resultó sencillo, debido a factores de diversa índole: por un lado, la propia dinámica de la investigación, siempre sometida a plazos, patronazgos, presupuestos y demás condicionamientos y, por otro, la dificultad de hacer valer nuestras reflexiones "más abstractas» o «teóricas» junto con las demandas de propuestas concretas y prácticas de acción de la comunidad docente.

En este último sentido, advertimos la "prisa» que ha suscitado la «masiva» presencia de «diferencia cultural» en las aulas (Carrasco, 2003), que encendió el piloto de alarma en la comunidad educativa. Contemplado como el escenario donde se reflejan los cambios de la sociedad, desde las instituciones educativas se reclama, a los distintos actores sociales, gestores y políticos, docentes, instituciones educativas y comunidad científica en general, que den respuestas rápidas, prácticas y útiles a los problemas que añaden «quienes llegan de fuera», quienes se entiende portan la diferencia cultural que da sentido a la 
«recién aparecida» interculturalidad en las aulas. Fue bajo estas premisas y bajo este contexto con lo que comenzamos, en el 2002, el contacto con los distintos colegios y —en paralelo- el debate, teórico y práctico, sobre educación, diversidad e interculturalidad en el marco del proyecto.

\section{Primeros contactos con la comunidad educativa}

Por el mes de mayo del año 2002, se nos requirió, en calidad de investigadoras de la Universidad de Granada y expertas en materia de interculturalidad, la organización de "algo", unas jornadas, un curso o un seminario que diera respuesta a una demanda que estaba siendo percibida por el Centro del Profesorado $(\mathrm{CEP})^{5}$ de la provincia de Huelva. El objetivo propuesto por los responsables de esta entidad era ofrecer actividades al profesorado que comenzaba a encontrar en sus aulas alumnado de origen inmigrante extranjero y requería soluciones ante los «nuevos problemas» que esta circunstancia suponía, tanto para la comunidad educativa en general como para la práctica docente en particular. Aquí es donde encontramos uno de los primeros tropos en torno a la educación intercultural y de los que, como investigadoras, establecimos una «vigilancia epistemológica» (Franzé, 2002).

\subsection{Educacion intercultural ante la llegada de alumnado inmigrante extranjero}

Uno de los «errores» fundamentales con los que tradicionalmente se trabaja cuando se habla de educación intercultural es la creencia de que ésta se hace necesaria únicamente a partir de la llegada de población inmigrante extranjera a las aulas. $\mathrm{O}$ bien como advertencia y/o preparación ante la futura presencia que se predice llegará a nuestras sociedades y a los centros educativos. Así se muestra en nuestro diario de campo cuando iniciamos los primeros contactos con el CEP y se explicitaron algunas de las razones por las que se mostraron interesados en la temática de la interculturalidad:

Algunas de las impresiones que más me interesa destacar sobre nuestra primera reunión con el CEP son las siguientes. En primer lugar, tienen un objetivo muy claro y es encontrar estrategias de qué hacer con la población inmigrante escolarizada que llega a sus centros educativos [...]. En segundo lugar, quieren formar al profesorado mediante la celebración de jornadas, conferencias, seminarios... no se ha hablado de la formación continua.[...] Otro aspecto que me interesa destacar de esta reunión es la percepción del contexto en cuanto a recepción de población inmigrante. Demandan educación intercultural no sólo por el volumen de escolares inmigrantes, que ya existe, sino además

5. Los centros del profesorado (CEP) «son las unidades de la Consejería de Educación y Ciencia (de la Junta de Andalucía) encargadas de la dinamización, planificación y desarrollo de la formación del profesorado en su zona geográfica de actuación» (artículo 8, decreto 110/2003, del 22 de abril, por el que se regula el Sistema Andaluz de Formación Permanente del Profesorado). 
por el que se "avecina que vendrá». (Diario de campo de una de las autoras del texto. Septiembre del 2002)

La vinculación entre inmigración e interculturalidad alienta el cuestionamiento y la necesidad de medidas relacionadas con: ¿cómo afrontar la enseñanza de la lengua española?, ¿cómo lograr establecer el contacto con las familias de alumnado inmigrante extranjero?, ¿cómo evitar su absentismo escolar?, ¿Cómo prevenir los conflictos xenófobos en los centros educativos? y, sobre todo, ¿cómo integrar su cultura en la escuela?

Estos interrogantes se nos plantean en la provincia de Huelva, en un contexto que, en los últimos diez años, se ha convertido en un «nuevo» espacio receptor de población inmigrante extranjera. Como ejemplo, la evolución desde el año 1992, momento en el que se contabilizaba un total de 1.978 extranjeros comunitarios y no comunitarios, hasta los 5.356 recogidos en las estadísticas en el año $2000^{6}$. En el cultivo agrícola de la fresa y los cítricos como actividad empresarial propia de la zona oriental de Huelva (comarca de la Costa y comarca del Condado), se demanda cada vez más mano de obra que cubre la población extranjera inmigrante. Esta actividad económica encierra un importante carácter de estacionalidad que está desapareciendo gradualmente, debido a la intensificación de la agricultura y que conlleva un progresivo asentamiento de estos colectivos en la zona. La incorporación de extranjeros y extranjeras a los espacios cotidianos les hace cada vez más visibles a ojos de la población residente de los pueblos onubenses, quienes perciben que la composición de sus colegios, tiendas, plazas, servicios públicos... va cambiando debido a la presencia de gentes de distinto color, lengua, religión, costumbres...

En este marco, surge la preocupación de los CEP sobre cómo gestionar la interculturalidad que portan los inmigrantes en el aula. En el mes de octubre del año 2002, al tiempo que desarrollábamos nuestros primeros encuentros y contactos con la comunidad educativa, se nos concedió el proyecto CLIEC sobre interculturalidad junto a otros compañeros europeos ${ }^{7}$. Bajo los planteamientos del mismo, pudimos evidenciar cómo la demanda del espacio educativo y los intereses europeos de investigación no estaban tan distanciados, sino que tomaban sentido dentro de una misma lógica: el pensar en interculturalidad en el ámbito escolar remite de forma exclusiva a la presencia de extranjeros en el aula. Algo que hacía cuestionarnos si nosotras, como parte de la Academia, no estábamos de alguna forma contribuyendo a la cosificación y generalización que relaciona ambas nociones, en tanto que, de alguna manera, nosotras también estábamos «buscando» un escenario «ade-

6. Datos según el Anuario de Extranjería. Fuente: Esther MÁrQuEZ y F. Javier GARCía (2003).

7. En el proyecto CLIEC participaron las siguientes instituciones: Centre of Intercultural Education, de la Universidad de Gante (Bélgica) — país coordinador — junto a Intercultural Centre Iceland (Islandia), Centre for European Studies, Jagiellonian University (Polonia), Lauder Morasha Private Primary School (Polonia) y el Laboratorio de Estudios Interculturales de la Universidad de Granada (España). 
cuado", un contexto receptor de inmigración donde implementar un proyecto de «interculturalidad». Nos preguntábamos si, como analiza Favell, no eramos «académicos (que) contribuyen mediante sus investigaciones tanto a la construcción de los problemas sociales (cómo son percibidos) como a sus soluciones» (2003: 20).

En este sentido, no hay más que echar un vistazo a la literatura sobre educación intercultural y multicultural en el contexto español para percibir cómo, a partir de los años noventa, se ha producido un boom de trabajos teóricos y de intervención (desarrollo de programas educativos) sobre estos temas, momento en el que aparece en escena la presencia cada vez más numerosa de inmigrantes extranjeros no comunitarios y los hijos de éstos en las escuelas (García; Granados y García-Cano, 2000: 8). Dicho de otro modo, ¿no estábamos nosotras también instituyendo a los sujetos (escolares inmigrantes no comunitarios) en objetos de estudio de la «interculturalidad»? Parece inevitable que la respuesta no pueda ser más que afirmativa.

La justificación o explicación de tal hecho exige un análisis sobre el surgimiento del multiculturalismo como movimiento social y discurso político y su imbricación en el mundo educativo. Como argumenta Dietz (2003: 13-48), es importante comprender el complejo proceso por el que ha ido pasando el multiculturalismo hasta construirse a sí mismo como movimiento social («búsqueda de una identidad colectiva»), análisis teórico (llevando a la «academización del multiculturalismo») y como acción política («mediante la conquista de espacios institucionales»). Todo ello ha contribuído de alguna manera a la «culturalización» del multiculturalismo y a la, no deseable, apropiación de un discurso que esencializa la "diferencia cultural» y «étnica» ante cualquier problema social. Es en este momento, tal como apunta Dietz (2003), cuando el discurso intercultural penetra en el sistema educativo y repercute en el proceso de institucionalización del mismo. El origen y la construcción del «multiculturalismo» y su penetración en el sistema educativo dirige el debate hacia el rendimiento de «minorías étnicas» o la presencia de alumnado procedente de otros contextos. Así, "su condición de inmigrantes» es la que acaba justificando la intervención pedagógica «intercultural»o «multicultural» ${ }^{8}$ (Dietz, 2003: 59).

Conscientes de la importancia que la presencia de población inmigrante ha supuesto en la inclusión de los discursos y de las prácticas interculturales en el sistema educativo, y con el objetivo de mitigar y de evaluar el efecto que dicha presencia generaba en el desarrollo de proyectos o actividades inter-multiculturales, decidimos ofrecer e implementar el mismo proyecto de educación intercultural, el CLIEC-AMIGHA, también en contextos donde la existencia de inmigrantes fuera muy poco significativa numéricamente hablando. Pretendíamos precisamente ponerlo en práctica en lugares como la comarca

8. Diversos autores coinciden en distinguir entre multiculturalismo e interculturalidad. Con el primer concepto se refirieren a «la yuxtaposición o presencia de varias culturas en una misma sociedad» (Muñoz, 1997: 120), mientras que por interculturalidad entiende la interrelación entre culturas. 
de Los Pedroches, Córdoba, donde la diversidad dentro del aula no fuera pecibida como «cultural» o «étnica», donde la llegada y la presencia de «los otros» aún no era tan significativa.

El paralelismo europeo de dicha situación lo encontrábamos con la participación del socio islandés, país con el índice más bajo de inmigración de toda Europa ${ }^{9}$. Allí, la implementación de las unidades CLIM en los colegios de primaria pretende hacer uso de la diversidad interna entendida ésta en plural, desde una concepción más amplia y compleja, no reducida a diferencias de color, origen étnico o nacionalidad. Lo que se intenta conseguir en este contexto es hacer un uso de la diversidad aprehendida desde todas sus dimensiones (Batelaan y Van Hoof, 1996), objetivo central en el proyecto CLIEC-AMIGHA. Esto es, incluyendo diferencias de lengua/dialecto, religión y sistemas de valores, conocimientos y destrezas, estatus académicos/talentos intelectuales, etnicidad y nacionalidad, estatus legal, bagaje socioeconómico (clase social), origen geográfico (rural/ urbano), género y orientación sexual, edad, posibilidades físicas, historia personal, condiciones familiares, etc.

Sin embargo, en contextos caracterizados «aún» por la «no inmigración», no obtuvimos la respuesta que nos hubiera gustado debido a la inexistente implicación, por parte del profesorado, para realizar actividades interculturales. Bajo esta lógica de entendimientos, como no podía ser de otra forma, si no hay extranjeros, se interpreta que no hay interculturalidad, por lo que carece de sentido abordar dimensiones de «una realidad que no existe». Es significativo recordar, no obstante, cómo se nos recomendó ofertar el proyecto de educación intercultural en un colegio muy concreto de la comarca, así como en los centros de educación de adultos, donde el profesorado se estaba encontrando con una falta de estrategias didácticas para la enseñanza de la lengua castellana.

En el primer caso, el colegio recomendado es un centro público situado en una zona donde el alumnado que tradicionalmente asiste posee los niveles socioeconómicos más bajos de toda la ciudad. En este colegio es donde se está comenzando a concentrar el alumnado extranjero inmigrante que reside en el municipio (fundamentalmente, de origen rumano y marroquí), llegando a ser un colectivo de 22 alumnos de origen extranjero sobre un total de 300 alumnos nacionales matriculados en el curso 2003-2004. De nuestros primeros contactos con el Equipo de Orientación Educativa de la zona, queremos destacar dos aspectos de interés que se refieren al modo en que se aborda y se maneja el tratamiento de la presencia de inmigrantes. Por un lado, el volumen de alumnado extranjero matriculado era calificado como "avalancha» en un municipio que definían de escasa tradición de «inmigración». Y, por otro lado, relacionado con lo anterior, nos argumentaban cómo la imagen de dicho colegio se asociaba directamente con la «marginalidad», siendo un motivo explícito por parte de la población en general para el no ingreso de sus hijos e hijas en dicho centro escolar. Hecho que ha dado lugar, en los últimos años y al 
comienzo de cada curso académico, a numerosas situaciones caóticas, como, por ejemplo, la saturación del censo de escolares en colegios de otras zonas.

En el segundo caso, los centros de educación de adultos, la demanda de este tipo de proyectos sobre educación intercultural estaba motivada por la "supuesta» escasez de recursos del profesorado ante un alumnado que necesitaba nuevos contenidos de aprendizaje (en este caso, el aprendizaje del castellano). Algo que nos llevó a considerar que tanto nuestra experiencia como nuestro análisis no hacían sino ilustrar a nivel local algo que ya habían apuntado Kindcheloe y Steinberg (1999):

[...] el multiculturalismo aparece como el ojo de un huracán social que se arremolina en torno a los cambios demográficos que están ocurriendo en las sociedades occidentales. Los países occidentales -incluidos Estados Unidos, Reino Unido, Canadá, Australia y Nueva Zelanda - han experimentado una inmigración y varios movimientos de concienciación racial y de género que los han obligado a enfrentarse a cuestiones relativas a su propia definición y a las de otras instituciones sociales. (Kindcheloe y Steinberg, 1999: 25)

$\mathrm{Al}$ igual que el profesorado cordobés, el de la provincia de Huelva que participa en el proyecto CLIEC-AMIGHA vinculaba la enseñanza de la lengua española con la educación intercultural, tal como lo explicaban en una sesión de trabajo en grupo cuando, de forma restropectiva, les pedimos que reflexionaran sobre las razones por qué les interesó participar en este proyecto:

Profesora 2: Yo lo que veo es que la idea que yo tenía de interculturalidad era muy distinta a lo que hemos visto aquí. Porque la idea que yo tenía de interculturalidad pues yo pensaba, solamente yo pensaba en niños de otras culturas, niños bien marroquíes, o de otros sitios, sin pensar en que los niños del propio pueblo que son diferentes. [...] Que interculturalidad no es sólo niños de otras culturas de otras partes [...]. (Transcripción de grupo de discusión celebrada en mayo del 2003)

Quedaba, así, claro que la educación intercultural era percibida y puesta en relación directa por parte de los profesionales de la educación con los que estábamos en contacto, con la presencia de población extranjera «inmigrante».

\subsection{Explicitando el cuándo de la educación intercultural}

Nuestro punto de partida asume la idea explícita según la cual, cuando hablamos de educación intercultural, no nos referimos a problemas o a cuestiones asociadas o relacionadas directamente con la inmigración. La llegada de población extranjera inmigrante a las sociedades receptoras y a nuestras aulas puede estar provocando problemáticas relacionadas con la adaptación lingüística o con el rechazo por parte de la sociedad de acogida, pero nuestro planteamiento parte del convencimiento de que esto en exclusiva poco tiene que ver con la 
interculturalidad. $\mathrm{O}$, dicho de otra manera, es una forma muy restringida, parcial y engañosa de abordar la interculturalidad. Es por ello que se trataba de cuestionar y replantear los esquemas de percepción desde los que abordamos a la población extranjera, evidenciando que la diversidad (incluso la cultural) no es aportada exclusivamente por la población inmigrante (Agrela, 2006).

Desde el proyecto AMIGHA, por tanto, el cuándo se debe intervenir sustituye a la premisa «ante la llegada de población inmigrante» por la de «ante la diversidad, entendida ésta en todas sus facetas». Este giro en la interpretación supone una nueva concepción de la sociedad y la propia educación, entendidas desde el reconocimiento de que vivimos en una sociedad que es multicultural per se, es decir, caracterizada al mismo tiempo por diversidades muy heterogéneas y que dichas diversidades conducen, en las relaciones de convivencia, a la desigualdad de ciertos grupos o colectivos concretos. La educación intercultural, en consecuencia, no será una mera asignatura, un modo o una estrategia sobre cómo enseñar en el aula, sino que es el medio para entender y organizar el currículo y el modo de educar en el respeto y la igualdad de oportunidades de forma transversal a todos los conocimientos. En este sentido, desde el proyecto AMIGHA, se parte de la consideración de que las políticas educativas en las sociedades occidentales democráticas tienen - $\mathrm{o}$ deberían tener- como objetivo el fomento y el desarrollo de la igualdad de oportunidades de todos los sujetos y grupos sociales, bajo el presupuesto de que democracia implica pluralismo y respeto de las diferencias (Batelaan y Van Hoof, 1996). La educación intercultural, de esta forma, será un modo de educación para todos que aglutine en la práctica la diversidad desde todas sus facetas de clase, género, cultura, etc. frente a aquellos posicionamientos que plantean la atención a determinados grupos en función de capacidades o situaciones sociales muy concretas.

\section{Revisión de presupuestos teóricos: el discurso cultural}

Hemos relatado la experiencia que tuvimos ofertando el proyecto de educación intercultural y la exclusiva asociación que se establecía con la llegada de población inmigrante. Es por ello que, a partir de tales percepciones y discursos, no nos resultara extraño que muchos colegios, una vez asignado por la Unión Europea el proyecto Comenius, fueran reacios a participar en una experiencia de educación intercultural, argumentando que no contaban apenas con población de origen inmigrante extranjero en sus censos escolares. En la medida en la que uno de los objetivos de nuestro proyecto pasaba por cuestionar y redefinir las nociones sobre las que se construye la idea de interculturalidad, consideramos prioritario desvelar, en primer lugar, algunas de las claves que dan sentido a la lógica discursiva que justificaba la interculturalidad en determinados contextos. Partíamos de la premisa teórica y de la convicción empírica según la cual la praxis de la educación intercultural viene justificada la mayor parte de las veces no tanto, o no exclusivamente, por la presencia de población inmigrante extranjera, sino más bien por la asociación de dicha pre- 
sencia con el concepto de «diferencia cultural», convertido éste en panacea de la diferencia y desigualdad y, por tanto, en vehículo de «desplazamiento y ocultación de realidades de la desigualdad social» (Carrasco, 2003).

Para hacer emerger los elementos que el profesorado manejaba para sostener dicha premisa, realizamos, como punto de partida, un primer taller de reflexión abierto a todos los centros. Con la intención de provocar una primera reacción sobre las expectativas del profesorado, estratégicamente lo titulamos La educacion intercultural más allá del inmigrante ${ }^{10}$. Se trataba de examinar y analizar el discurso cultural y "culturalista» ${ }^{11}$ que rodea a la interculturalidad y la inmigración, tanto a nivel discursivo como en las prácticas educativas.

\subsection{Educación intercultural "porque los que llegan tienen una cultura muy distinta a la nuestra»}

Hasta hace muy poco, el debate sobre la diversidad existente en el sistema educativo español era conceptualizada por razones de clase social, género o diferencias personales, tales como discapacidades físicas, intelectuales o sensoriales. El reemplazo actual de este discurso se ve empujado por la llegada de los hijos e hijas de inmigrantes extranjeros, la mal llamada «segunda generación», que ha propiciado la reflexión en torno a cuestiones como «dificultades de integración socioafectiva, la desafección a la escuela, el fracaso escolar, la "hostilidad" al medio, los conflictos intergeneracionales e intrafamiliares, etc.». Esta nueva diversidad "se explica predominantemente en términos de "choque cultural"" (Franzé, 1998: 127). Es decir, diversidad entendida como "su cultura» frente a «la nuestra». Así lo expresaba uno de los profesores a los que entrevistamos al comienzo del proyecto AMIGHA:

[...] aquí, pues yo creo que es la cantidad de personas de fuera, vamos, personas diferentes, de diferentes culturas, de diferentes razas de más con las que estamos conviviendo constantemente en el colegio y demás [...] Es como si tuvieras distintas clases diferentes porque entre árabes, lituanos, rumanos... era un grupo bastante numeroso lo que hemos tenido, y eso son diferentes culturas y diferentes formas de ver las cosas, de sentirlas y la verdad es que son difíciles.... y sobre todo en el colegio. (Maestra de educación especial, 24 de febrero del $2003^{12}$ ).

10. Dicha sesión de trabajo estuvo a cargo del profesor Gunther Dietz, profesor titular de Interculturalidad y Educación de la Universidad de Granada y coordinador, junto a María García-Cano y Esther Márquez, del proyecto CLIEC en España.

11. Concepto al que Gregorio y Franzé (1999) se refieren haciendo alusión a la tendencia a plantear las problemáticas socioeducativas en clave etnocultural o de pertenencia a una comunidad de origen.

12. Con el objetivo de mantener la confidencialidad de las personas informantes, identificamos las entrevistas señalando: el sexo del informante (maestro/maestra), la asignatura o especialidad que imparte y la fecha en la que se realizó dicha entrevista. 
El concepto de cultura aparece en ésta y en otras declaraciones de manera simplista y homogeneizante, suponiendo a la cultura cierta consistencia sustantiva y delimitable, convirtiéndola así "en fuente de explicaciones por sí misma» (Kuper, 2001: 13). Estos discursos que entienden la cultura de manera cosificadora y finita conllevan una apreciación, cuando menos, parcial y engañosa de la misma y, por consiguiente, del concepto de interculturalidad:

Esto no significa que alguna forma de explicación cultural no pueda ser útil por sí sola, pero sí supone que la apelación a la cultura únicamente pueda ofrecer una explicación parcial de por qué la gente piensa y actúa como lo hace, o de cuáles son las causas que los llevan a alterar sus maneras y costumbres (Kuper, 2001: 13).

\subsection{Explicitando el por qué de la educación intercultural}

Para trabajar con el profesorado sobre la deconstrucción de esta concepción con la que identifica el por qué de la educación intercultural relacionándolo de manera directa con la "diferencia cultural», hasta el punto de reducir problemáticas o situaciones de carácter social o económico con argumentos «culturales», consideramos necesario plantear al profesorado algunas de las cuestiones sobre las que se asientan este tipo de inferencias. Para ello, organizamos distintas sesiones de formación y éstos fueron algunos de los argumentos que utilizamos en ese primer intento de acercarnos y acercarles la interculturalidad más allá de la inmigración.

1. Superación de una visión esencializadora de la cultura y la interculturalidad. Porque encontramos el concepto de interculturalidad compartiendo los mismos supuestos que el concepto de cultura, que, aunque superados en el último cuarto de siglo, vuelven a poner a debate el cuestionamiento de si las culturas humanas "¿existen como entidades ónticas, inmutables en su esencia, o son constructos humanos, históricos y por lo tanto sujetos a procesos de cambio?» (Dietz, 2003: 80). La concepción de la cultura como algo homogéneo y simplista, no representante del carácter complejo e híbrido actual, ha conducido no sólo a poner el acento en las diferencias entre «culturas» (o entre «civilizaciones» en palabras de Huntington, 1996), sino, sobre todo, a la negación de las diferencias intraculturales (García García, 1996: 2). Los efectos que este modo de concebir la diversidad tiene conllevan la categorización de grupos de población, homogéneos en su interior, en oposición a «los otros», grupos identificados por su «esencia» hasta cierto punto "con cierta consistencia sustantiva y delimitada» (García García, 1996: 1). Las personas son percibidas exclusivamente en tanto que identidades culturales (Agrela, 2006a).

En contextos de inmigración, el «uso y abuso" del calificativo de "cultural» lleva a percibir casi de manera automática la consideración de que las prácticas y los comportamientos del grupo al que pertenecen «los de fuera» (identificados como grupo en función de la nacionalidad, el continente o la región 
de origen ${ }^{13}$, el grupo religioso o la lengua que habla, entre otros argumentos) son estáticas, cerradas (Carrasco, 1997: 14) y, por supuesto, generalizables a todo el grupo. Y son esas prácticas culturales diferentes las que se han convertido en baluarte y justificación para la puesta en marcha de proyectos de educación intercultural.

2. Cultura entendida como algo profundo e inmutable que la educación o la interacción entre grupos no puede cambiar. Porque si rastreamos en la disciplina antropológica y las distintas definiciones que se han ido elaborando sobre el concepto de cultura, nos encontramos con aquellos autores que la han definido como ese conjunto de aspectos (entre los que se incluyen conocimientos, creencias, arte, moral, costumbres, hábitos... y un largo etcétera (Tylor, 1987)), que dotan a un grupo de cierta consistencia interna. Es decir, existe algo, la cultura, que es identificable y que caracteriza a los individuos de un grupo, hasta tal punto que aún sustituyendo los argumentos biologicistas de identificación de las diferencias entre grupos, ahora es la cultura el argumento capaz de explicar e identificar dichas diferencias haciendo coincidir diferencias culturales con nacionalidad. Este mecanismo ha sido identificado por la autora Stolcke (1991) de «fundamentalismo cultural» o, lo que es lo mismo, la naturalización de lo social y de determinados elementos o factores culturales, siendo las diferencias entre grupos identificadas como incompatibles para el modo de vida del otro.

El problema fundamental que encontramos en este tipo de definiciones o de concepciones del concepto de cultura es la poca dinamicidad y capacidad de interpretación y re-construcción que otorgamos a la misma. Es decir, tendemos a cosificar y asignar cultura a los miembros de un grupo, en vez de inferir la cultura de dicho grupo. Éste es el caso cuando nos referimos a la población que llega de contextos exteriores, aquella que identificamos o creemos muy diferente «al nosotros», nos resulta muy fácil marcarle las fronteras, asignarle una serie de características culturales que, por un lado, pensamos son muy distantes a las nuestras $y$, por otro, las identificamos tan propias al grupo que incluso adoptan el criterio de «naturales». Delgado (2000) lo explica de la siguiente forma:

El supuesto «inmigrante» o "étnico» se ve atrapado en una vida privada de la que no puede escapar, puesto que se le imagina esclavo de sus costumbres, prisionero de su cultura, víctima de una serie de trazos conducturales, morales, religiosos, familiares, culinarios que no son naturales, pero que es como si lo fuese, en la medida que se supone que lo determina de una manera absoluta e invencible, a la manera de una maldición. (Delgado, 2000: 134)

13. Como ejemplo, aquellos casos en los que se utilizan de manera sinónima «los marroquíes», «los magrebíes», «los musulmanes» o "los árabes» para referirse al mismo grupo de personas. 
Dentro del ámbito educativo, en muchos casos ese inmovilismo otorgado a la cultura aparece junto a mensajes de respeto y enriquecimiento mutuo, al interaccionar los diferentes grupos culturales: los extranjeros y los nacionales. Esto responde más a la expresión de una deseabilidad social de convivencia pacífica que a la comprensión y aceptación de cómo, en situaciones de igualdad entre diferentes grupos, la cultura se reconstruye, cambia y da lugar a nuevas formas de actuar que afectan a ambos grupos. Así era como una profesora nos definía lo que, según ella, debía ser la interculturalidad en educación, «riqueza cultural aunque todo permanezca según su propia esencia»:

Pienso que educar interculturalmente debe ser lo bueno de los distintos sitios y que esos niños lo asuman, no que cambien sus hábitos o que cambien..., sino que vean que existen otras culturas y que tienen cosas tan bonitas o más bonitas que la suya. Entonces es un enriquecimiento [...]. (Maestra, tutora del tercer curso de primaria, 24 de febrero del 2003)

3. Tendencia a convertir «la diferencia cultural» en desigualdad, esto es, a establecer jerarquías entre «culturas». Éste fue el último de los ejes argumentales que abordamos y que consideramos fundamentales de revisión, porque deriva precisamente del modo de concebir la cultura de forma esencialista, homogénea intraculturalmente e inamovible. Se clasifica para ordenar, y esta ordenación casi siempre lleva implícita una comparación y creación de escalas en torno a las cuales se identifican las «identidades colectivas de pertenencia». Aspecto que ha generado ciertas definiciones de "etnicidad» ${ }^{14}$ y en otros casos del "nacionalismo" deudoras de estas concepciones epistemológicas. Establecemos casi de manera automática mecanismos cognoscitivos de categorización que nos conducen al establecimiento de desigualdades y jerarquías que sitúan a ciertos grupos en situaciones de desventaja social y que se refleja en múltiples aspectos de la vida social como es la discriminación, la explotación o la exclusión, ya sea para el acceso a los recursos sociales, el empleo, etc. Cuando asociamos las diferencias fenotípicas con pertenencia nacional, diferente lengua o religión, dicha desigualdad está más que servida.

En el ámbito educativo, esas diferencias y desigualdades establecidas sobre el grupo se proyectan y se refuerzan, lo que afecta al proceso de enseñanzaaprendizaje. Como afirma Díaz-Aguado (2003), las expectativas del profesorado hacia el alumnado se construyen sobre la base de aspectos tales como la clase social, el grupo étnico de pertenencia y la conducta que refleje el alumnado en clase, siendo interesante observar cómo:

14. Definimos etnicidad siguiendo a Dietz (2003: 84) «como aquella forma de organización de grupos sociales cuyos mecanismos de delimitación frente a otros grupos con los que se mantiene algún tipo de interacción, son definidos por sus miembros a partir de rasgos considerados distintivos de las culturas que interactúan y que se suelen presentar con un lenguaje biologizante, por ejemplo, recurriendo a terminología de parentesco y ascendencia». 
Cuando la conducta que el niño manifiesta en clase (facilidad para el aprendizaje, cumplimento de normas...) se acomoda al currículum oculto y va claramente en contra de los prejuicios existentes hacia el grupo al que pertenece, no suele ser muy difícil para la mayoría de los profesores percibir al alumno con precisión, como un individuo, al contrario de lo que sucede cuando la conducta del niño va en la misma dirección de dichos prejuicios y en contra del modelo de alumno que tiene el profesor. (Díaz-Aguado, 2003: 33).

Estos prejuicios o imágenes que elaboramos sobre el «otro extranjero» no nacen de inmediato, sino que son fruto de largos procesos sociohistóricos en los que se va condicionando y moldeando nuestra forma de pensarlos y actuar respecto a ellos (Madariaga, 2001: 117). Es interesante destacar la distinta valoración que, desde el sistema educativo, se ejerce ante individuos por el simple hecho de pertenecer a una determinada comunidad de origen frente a otros. Siendo precisamente éso, las características que se le atribuyen a las diferencias de carácter nacional (o de origen)-religioso-étnico del grupo de pertenencia, los criterios que sirven de valoración y de explicación de determinados comportamientos del individuo, obviando sus propias características, condicionantes particulares y formas de vivir e interpretar $s u$ cultura, religión, clase social o situación familiar.

Frente a este tipo de consideraciones en las que la educación intercultural se ha venido justificando con argumentos de carácter «cultural»o «culturalista», nuestra propuesta teórica y de intervención desde el proyecto CLIECAMIGHA partía del reconocimento de que la diversidad y la desigualdad en el aula no provienen de la pertenencia a grupos de "diferente cultura», «raciales» o de nacionalidad distinta, sino que son fruto de la coexistencia no reconocida de diferentes formas de interaccionar en el aula. La educación intercultural no debiera considerarse como la «educación para las minorías» en la que se tiende a estereotipar y segregar al alumnado de origen inmigrante, asignándole una etiqueta impuesta en la que se detallan todos los estereotipos que la sociedad receptora tiene construidos sobre tal o cual "cultura» de pertenencia (FETE, 2001: 15). Muy al contrario, proponemos una educación que analice las distintas formas de interacción del alumnado en el aula que nos permita descubrir que, en realidad, muchos de sus referentes y significados tienen más aspectos en común con sus iguales de lo que estamos dispuestos a reconocer, lo cual permite realizar el trabajo en interacción en favor de la igualdad y el respeto de la diversidad, abandonando posturas esencialistas y reificantes incapaces de reconocer los lazos sincréticos que los hijos de inmigrantes establecen con gente de su edad de otros grupos (Rex, 1995: 204). En el plano más empírico, entendemos que no se trata, por tanto, de otorgar tratamientos o derechos diferenciales de acuerdo con las adscripciones étnicas o el origen familiar; como señala Vila (2004), porque las dificultades del alumnado en el aprendizaje son mucho más iguales que diferentes, por lo que, desde la educación intercultural, deberíamos vernos más desde las semejanzas y la igualdad que desde las diferencias. Entendidas además éstas últimas a partir de una 
noción amplia y compleja de qué produce la diferencia, más allá de la sola condición de extranjería. La clave no está sólo en comprender qué produce diferencia, sino en cómo esa diferencia y según en qué colectivos se traduce en desigualdad.

Entenderemos así la diversidad en un sentido amplio y flexible, reconociendo las distintas formas de generar diferencia, en función del tipo y el volumen de capital del que disponen los miembros de una sociedad. La distribución desigual en el espacio social entre los individuos y grupos - a merced de la incorporación y el volumen de capital o capitales - genera por sí misma posiciones sociales desiguales. De este modo, las diferencias entre individuos y grupos constituyen procesos complejos fruto de la interacción entre tres tipos de capital: el capital económico, que, de forma directa o indirecta, se convierte en dinero; el capital cultural, apropiado para la institucionalización sobre todo cuando se manifiesta en forma de títulos académicos, y que puede ser convertible en capital económico, y, por último, el capital social, relacionado con las obligaciones y las relaciones sociales, definido como "la totalidad de los recursos potenciales o actuales asociados a la posesión de una red duradera de relaciones más o menos institucionalizadas de conocimiento y reconocimiento mutuo" (Bourdieu, 2000: 148). Esta tipología tripartita de capitales nos llevará a entender la cultura de un modo fluido, que atiende a la relación entre la generación de identidades colectivas en los grupos creadas sobre una base económica, las pautas específicas de socialización y los procesos políticos de regulación de las distintas formas de hacer que actúan, en sí mismas, como representaciones simbólicas.

Éstas fueron, a modo de resumen, algunas de las ideas y de los razonamientos que compartimos y trabajamos con el profesorado. Tocaba, a continuación, dar un paso hacia adelante concretando en propuestas las maneras con las que operacionalizar y llevar a la práctica esta noción de educación intercultural. Para ello nos fue de gran utilidad servirnos de distintas experiencias europeas como punto de referencia donde encontrar claves para la aplicación.

\section{Actuaciones interculturales en el ámbito escolar}

A mediados de los años setenta, el Consejo Europeo puso en marcha la educación intercultural como proyecto, incentivando actuaciones que, de forma general y con ciertas variaciones según los distintos contextos, pasaban por el reconocimento de "otras culturas" referidas a la presencia de inmigrantes — extranjeros - o grupos minoritarios. Como exponen Verlot y Pinxten (2000), los distintos significados, en ocasiones contradictorios y complementarios a la vez, han oscilado desde el énfasis por el conocimiento acerca del «otro» hasta por la enseñanza de actitudes de tolerancia y de «respeto de las diferencias». Destacan, entre estas experiencias, la influencia del Reino Unido y su proyecto de educación antiracista, en paralelo a la experiencia norteamericana, centrada en torno a los problemas de discriminación por el color de la piel (Rex, 
1995: 198), dejando al margen los problemas derivados por las diferencias culturales, muy relevantes en el resto de países europeos. Existen, por tanto, varias opciones entre las respuestas «interculturales» que el sistema educativo europeo ha fomentado, generando diferentes debates en torno a las «políticas de identidad» que han acompañado a las medidas educativas en los distintos estados. En términos generales, podríamos distinguir, por una parte, entre los planteamientos y las propuestas que plantean la «multiculturalización» de los sistemas educativos desde la "acción afirmativa" y la "discriminación positiva" de los grupos minoritarios, más propia del ámbito anglosajón; frente a, por otra parte, la tendencia seguida en los países continentales europeos, donde la «interculturalización» de los sistemas educativos se entiende y se propone como desafío a las sociedades pretendidamente homogéneas, en respuesta a la heterogeneidad y diversidad de las mismas. La diferencia entre ambos contextos, llegamos a la conclusión de que se centraba en la tendencia empoderadora de las minorías en el Reino Unido y Estados Unidos frente a la educación transversal, dirigida tanto a minorías marginadas como a los grupos mayoritarios que marginan (Dietz; García-Cano y Márquez, 2004: 2), carácterísticas del ejemplo francés.

Las referencias a la educación intercultural que habíamos encontrado en nuestro trabajo de campo estaban a medio camino entre esa tendencia seguida en el contexto continental europeo y un proyecto asimilador, en un híbrido que pasaba por dotar de competencias interculturales al alumnado pero centradas únicamente en el grupo minoritario. Y fue ahí donde encontramos el tercero de los tropos relacionados con la educación intercultural: la educación intercultural como solución a situaciones calificadas de problemáticas o conflictivas. Algo que nos ha exigido una constante vigilancia, tanto teórica como en el análisis de las actuaciones que, en la práctica educativa, venimos desarrollando.

Cuando preguntamos a los maestros y a las maestras si en los centros educativos donde imparten docencia sería necesario llevar a cabo proyectos de educación intercultural y cuáles serían las razones para ello, encontramos respuestas que, de manera explícita, vinculan inmigración con una situación conflictiva. Ocurre para aquellos casos en los que se aboga por la interculturalidad, tanto en referencia a la presencia de hijos de inmigrantes extranjeros, como en aquéllos otros en los que se alude a grupos nacionales pero entendidos como minorías étnicas, fuertemente estigmatizadas, como es el caso del colectivo gitano asentado en España. Veamos un ejemplo al respecto al hilo de la pregunta de por qué considera necesario el desarrollo de proyectos de educación intercultural en su localidad:

[...] porque se está viviendo un poco con la actividad económica aquí de la zona, nos encontramos con mucha mezcla, mucha mezcla y grupos y entonces los grupos cuando no están, cuando se sienten aislados yo creo que son más problemáticos que cuando están unidos y ahí en plan racial pues los ves en la plaza pero cada... y se le mira con un poco de rechazo. Bueno, ahora están los 
moros comprando, ahora no se puede ir, y en cualquier sitio se les mira así, si todo el mundo te mira de otra manera pues no es muy bueno... (Maestra de sexto de primaria, 24 de febrero del 2003)

Según estas declaraciones, y aunque no se menciona a ningún grupo minoritario, la educación intercultural tiende a relacionarse de manera directa con la promoción de valores democráticos y de conviviencia pacífica en situaciones de conflictividad, situando a la institución educativa como la responsable y custodiadora del bienestar social. De este modo, la promoción de la educación intercultural se interpreta como una continuación de lo ya existente, del trabajo en valores que el profesorado entiende y transmite, o "debería» transmitir, en cualquier circunstancia al alumnado, de la labor educativa inherente a la propia institución escolar. La escuela, como el espacio formal desde el que se enseña a ser ciudadano de un estado bajo unos determinados valores, normas, cultura... imprime, en definitiva, un modelo concreto (y homogéneo) de sociedad, que lleva implícita una idea específica de diversidad "controlada» o aceptada.

Así, son muchos los casos en los que el profesorado nos explicaba cómo su interés en el proyecto CLIEC-AMIGHA estaba vinculado al desarrollo de otro tipo de programas en los que estaba implicado su colegio y que tenían que ver con "proyectos en valores» entre los que consideraba de máxima importancia añadir la tolerancia, el respeto y la aceptación de la «diferencia cultural».

Yo creo que ser capaz de respetar y de convivir con el que tienes al lado, ya está. Que sea, si hablamos de culturas porque vienen de otro país, porque tienen otras formas, otras costumbres, a cualquiera, yo que sé, por lo menos, pues intentar trabajar en valores... enseñar algunas cosas del país o enseñar algunas palabras o que te sientas, algo así... o tú le dices a uno y tu padre qué es... cuéntanos algo del trabajo de tu padre... no sé que se sientan bien... (Maestra de educación especial, 24 de febrero del 2003)

Junto a este tipo de problemas de carácter social o económico identificados por el profesorado, extraemos una serie de demandas que también relacionan de manera directa la intervención en interculturalidad con la solución de cuestiones didácticas.

1. Educación intercultural vinculada a la enseñanza de la lengua y la cultura del país receptor. No hay duda que, tras esta afirmación o intento de desarrollar la interculturalidad, se esconden los bienintencionados deseos de «igualar las oportunidades educativas» de todos y cada uno de los alumnos en la escuela y, en los casos de inmigración, con aquéllos que no hablan la lengua del lugar de destino. La contrapartida de este modo de «igualar las oportunidades educativas» la encontramos en los intentos de asimilación de «los culturalmente diferentes» al currículum y la cultura del grupo dominante (la sociedad 
receptora) y lo que ello supone de negación de las diferencias y, por tanto, de uniformización, homologación o absorción cultural.

Tiende a relacionarse la presencia de alumnado extranjero con fracaso escolar, dada la constatación de los datos, tanto en España como en otros países. Los desacuerdos pasan, sin embargo, por las argumentaciones a partir de las que se explica dicho fracaso. Se pone el acento sobre la enseñanza de la lengua del país de destino, por lo que se apuesta por estrategias didácticas normalmente ajenas a la dinámica cotidiana con el resto de compañeros y compañeras, de refuerzo de las competencias lingüísticas y comunicativas del alumnado recién llegado. Así, una de las demandas más exigidas por parte del profesorado cuando se le pide que describa en qué consistiría un programa de educación intercultural, hace referencia a la necesidad de dotarse de herramientas didácticas que posibiliten la comunicación del alumnado inmigrado en la sociedad receptora:

Desde como poder enseñar nuestra lengua, que es algo súper importante. El último caso aquí ha sido una chica de tres años, ¿polaca? ¿Podrá ser? Que la pobrecita harta de llorar porque no sabía comunicarse. Entonces, se entiende que tiene tres años, una maestra, por muy preparada que esté, pues no..., pero que tengamos una serie de recursos, no sé... unas tarjetas..., no sé... recursos para el profesorado para que no nos veamos con las manos vacías... cuando nos llegue esa circunstancia en concreto..., después, con la voluntad de otros alumnos... (Maestra de música, 26 de febrero del 2003)

Como vemos en las declaraciones de esta profesora, pero también de forma general en el discurso de muchos docentes, se insiste en la asociación de educación intercultural como respuesta a determinadas necesidades didácticas, lo que, desde nuestro punto de vista, supone, en primer lugar, una reducción en el análisis explicativo de las causas del fracaso. Esta focalización casi exclusiva hacia el hecho de aprender castellano no es suficiente si no se dominan habilidades lingüístico-cognitivas que se adquieren fuera de la institución escolar. Pero, además, la exclusividad por lo lingüístico deja de lado una explicación que integra aspectos más globales — condicionantes sociales, económicos y personales - tales como las condiciones de vida, las expectativas educativas familiares, la autoimagen o la autoestima, que también influyen de forma determinante en el éxito o en el fracaso escolar (Vila, 2004) y que son igualmente comunes a alumnado extranjero y español.

En segundo lugar, estas explicaciones cimientan una concepción restringida y parcial de lo intercultural. Esto no significa que en la clase no existan este tipo de necesidades educativas o que deban ignorarse por parte del profesorado. Pero si estas demandas, además, son percibidas como "problemáticas» o situaciones de difícil solución desde los recursos existentes en el colegio, se pueden generar en el aula dinámicas educativas que poco tienen que ver con una atención integral a la diversidad y sí mucho que ver con la problematización de una determinada realidad. 
2. La enseñanza de la lengua de destino suele estar acompañada de una serie de aspectos culturales identificados como propios de la sociedad de acogida y que configuran - desde un discurso emic - la «identidad cultural de la propia sociedad». Es decir, la incorporación y el éxito escolar, relacionados con los dos elementos básicos que conforman la idea de la cultura de un estado: la inmersión en la lengua y las costumbres. Por ello, no nos resultó extraño encontrar discursos que aunaran la necesidad de enseñar la lengua junto a la necesidad de enseñarles «nuestra cultura, lo nuestro, nuestras fiestas y tradiciones, nuestras comidas, nuestra religión y folclore». Los argumentos que justifican o explican el por qué o para qué de dichos contenidos es el de hacerles la estancia en el nuevo contexto más fácil, facilitarles el tránsito de «su» cultura a la «nuestra», de favorecer un arraigo y un sentimiento de pertenencia, que conozcan y «sepan cómo desenvolverse en el nuevo contexto en el que se encuentran».

\section{A modo de conclusión. Cuestionando cuándo, por qué y para qué la educación intercultural}

Nuestra experiencia de coordinación en este proyecto de investigación nos ha llevado a reflexionar y a cuestionarnos hasta qué punto la educación intercultural no está o estaba sirviendo en la praxis educativa y en el currículum escolar, incluyendo nuestros propios planteamientos, como un modo de tratar y redefinir las transformaciones identitarias que se están produciendo en los actuales estados nación (Dietz, 2003: 9), así como un modo de expresar cómo nos pensamos a nosotros, cómo nos concebimos y definimos nuestra propia identidad y nos presentamos frente al «otro». Ejemplo de ello fue la expresión, por parte del profesorado que tomaba parte en las actividades del proyecto, de elaborar materiales didácticos «interculturales» en los que se le mostrara a la población inmigrante extranjera residente en sus municipios las distintas fiestas y tradiciones típicas de la zona, es decir, aquellos elementos "culturales» que facilitaran la inmersión cultural y la convivencia con autóctonos, cuyo ejemplo más llamativo fue la alusión de realizar una "agenda sobre el Rocío» ${ }^{15}$.

Esta nueva constatación supuso para nosotras reafirmarnos en la idea de que, una vez más, la interculturalidad en la práctica respondía a la necesidad de "presentarnos frente a», de construirnos e identificarnos como grupo homogéneo al margen de las singularidades intragrupales, y esto también, desde el propio currículum educativo ahora llamado «intercultural». Por lo que consideramos que este concepto adolece de una profunda revisión, en aras de «sacar a la luz» los constructos culturales que subyacen detrás del mismo para, en un momento posterior, poder reflexionar en torno a las fronteras de nuestra propia identidad y la de esos «otros» extraños, que en este caso son visualizados en la figura del alumnado extranjero.

15. Fiesta de carácter religioso celebrada en la zona, ampliamente conocida en la región andaluza e incluso en el ámbito nacional, dado el carácter festivo y la proyección realizada por los medios de comunicación. 
Con este propósito y a partir de los presupuestos que hemos desarrollado en este artículo, es desde donde seguimos reflexionando e investigando ${ }^{16}$, siendo conscientes que la ejecución en las aulas y en los centros educativos abre nuevos debates y diferentes perspectivas en la realización de proyectos calificados de interculturales, pero que, como hemos visto, superan, transforman y redefinen las bases teóricas sobre los que se justifican.

\section{Referencias bibliográficas}

Agrela, B. (2006). «La figura "mujer inmigrante" en las políticas de acción social: De los discursos a las prácticas y los modelos de intervención». En: VV.AA. Mujeres inmigrantes, viajeras incansables. Bilbao: Harresiak Apurtuz, p. 75-93.

- (2006a). Análisis antropológico de las políticas sociales dirigidas a la población inmigrante. Departamento de Trabajo Social y Servicios Sociales. Universidad de Granada. Tesis doctoral (inédita).

BatelaAn, P.; VAN HoOF, C. (1996). "Cooperative learning in intercultural education». European Journal of Intercultural Studies, vol. 7, núm. 3, p. 5-16.

Bourdieu, P. (2000). Poder, derecho y clases sociales. Bilbao: Desclée.

CARRASCO, S. (1997). «Usos y abusos del concepto de cultura». Cuadernos de Pedagogía, 264, p. 14-18.

- (2003). «Antropología de la educación y antropología para la educación». En: GonZÁlez, A.; Molina, J. L. (eds.). Abriendo surcos sobre la tierra: Homenaje a Ramón Valdés del Toro. Barcelona: Publicacions d'Antropologia Cultural, UAB.

DELgaDO, M. (2000). «Inmigración, etnicidad y derecho a la diferencia. La antropología y la intervención de "minorías culturales" en contextos urbanos". En: CHECA, F.; CHECA, J. C.; ARJONA, A. Convivencia entre culturas: El fenómeno migratorio en España. Sevilla: Signatura Semos, p. 119-149.

DíAz-AguAdo, M. J. (2003). Educación intercultural y aprendizaje cooperativo. Madrid: Pirámide.

DiETZ, G. (2003). Multiculturalismo, interculturalidad y educación: una aproximación antropológica. Granada: Universidad de Granada y Ciesas.

Dietz, G.; García-CANO, M.; MÁrQUeZ, E. (2004). «Intercultural Education Facing the Challenge of Diversity: towards a comparative framework». Comunicación presentada en el seminario CIIMU Diversity and Inequality: Children's Experiences of Life and School in Multicultural Europe. Barcelona, enero.

FAVELL, A. (2003). «Integration nations: the Nation-State and research on immigrants in Western Europe». En: Comparative Social Research, vol. 22, p. 13-42.

FETE-UGT (2001). Inmigración y escuela: De la educación intercultural a la educación para la ciudadanía: Una propuesta para el debate. Madrid: IMSERSO.

FranZÉ, A. (1998). «Lo que sabía no valía. Trayectoria escolar y construcción de las relaciones entre iguales en la historia de Naima». Ofrim/Suplementos, diciembre, p. 125-141.

16. Con los proyectos Análisis de las competencias interculturales en el ámbito educativo y contextos de inmigración: significados y aplicaciones, financiado por la Dirección General de Coordinación de Políticas Migratorias de la Junta de Andalucía (2006-2007), y La gestión de la Educación Intercultural en los centros educativos: significados y alicaciones (2007-2008), también financiado por la Junta de Andalucía. 
- (2002). «Inmigración y escuela: algunas reflexiones teórico-metodológicas para su estudio». En: GARCÍA, F. J.; MuRIEL, C. (eds.). La inmigración en España. Contextos y alternativas. Ponencias del III Congreso sobre la Inmigración en España. Granada: Laboratorio de Estudios Interculturales, p. 591-600.

GARCÍA GARCÍA, J. L. (1996). «Sobre el significado y las consecuencias de la diversidad cultural». Ponencia presentada en el curso de verano Diversidad cultural, exclusión social e interculturalismo, de la Universidad Internacional de Andalucía. Baeza: Universidad Internacional de Andalucía.

García, F. J.; Granados, A.; GarcíA-Cano, M. (2000). Interculturalidad y educación en la década de los noventa: un análisis crítico. Sevilla: Consejería de Educación y Ciencia.

Gregorio, C.; FranZÉ, A. (1999). «Intervención social con población inmigrante: esos "otros" culturales". Intervención Psicosocial, vol. 8, núm. 2, p. 163-175.

MADARIAGA, M. R. (2001). «La imagen de Marruecos: la interpretación de la historia en el sistema educativo español». En: MARTín-MuÑOZ, G. (dir.). Aprender a conocerse: percepciones sociales y culturales entre España y Marruecos. Madrid: Fundación REPSOL-YPF, p. 117-150.

MÁrQUeZ, E.; GARCíA, F J. (2003). Guía de recursos para la atención de la población extranjera inmigrante en la provincia de Huelva. Granada: Laboratorio de Estudios Interculturales, Universidad de Granada.

MuÑOZ, A. (1997). Educación intercultural. Teoría y práctica. Madrid: Editorial Escuela Española.

Kincheloe, J. L.; SteinberG, S. R. (1999). «Introducción: ¿Qué es el Multiculturalismo?». En: Kincheloe, J. L.; STeinberG, S.; SteInberG, S. R. Repensar el multiculturalismo. Barcelona: Octaedro, p. 25-51.

Kuper, A. (2001). Cultura. La versión de los antropólogos. Barcelona: Paidós.

REX, J. (1995). «La metrópoli multicultural: la experiencia británica». En: LAMO DE EsPINOZA, E. (ed.). Culturas, estados, ciudadanos: una aproximación al multiculturalismo en Europa. Madrid: Alianza, p. 197-223.

STOLCKE, V. (1991). «¿Es el sexo para el género lo que la raza para la etnicidad?». Mientras Tanto, 48, p. 87-111.

VerLot, M.; PinXTEN, R. (2000). «Intercultural education and Complex Instruction. Some remarks and questions from an antropological perspective on learning». Intercultural Education, 11 suplemento, p. 7-14.

VILA, I. (2004). «Lenguas, cultura y diversidad humana: convivencia o conflicto». En: VV.AA. III Congreso de Necesidades Educativas Especificas y Atención a la Diversidad de la Comunidad de Madrid en el Año Europeo de la Discapacidad: Perspectivas, Logros y Avances. Madrid: Comunidad de Madrid. 